\title{
Fatsa-Sarmaşık Kaplıcasında Radon Aktivite Konsantrasyonunun Belirlenmesi (Ordu İli)
}

\author{
Selcen UZUN DURAN ${ }^{1 *}$, Belgin KÜÇÜKÖMEROĞLU², Halim TAŞKIN ${ }^{3}$ \\ ${ }^{1}$ Karadeniz Teknik Üniversitesi, Sağllk Hizmetleri MYO, Tıbbi Görüntüleme Bölümü, Trabzon \\ ${ }^{2}$ Karadeniz Teknik Üniversitesi, Fizik Bölümü, Trabzon \\ ${ }^{3}$ Türkiye Atom Enerjisi Kurumu, Çekmece Nükleer Araștırma Merkezi, İstanbul \\ (ORCID: 0000-0003-4943-4654) (ORCID: 0000-0003-3963-3764) (ORCID: 0000-0002-5195-1477)
}

\begin{abstract}
$\ddot{O} z$
Bu çalışmada, Karadeniz Bölgesinde az sayıdaki jeotermal kaynaktan birisi olan Fatsa İlçesi, Ilıca Köyü sınırları içerisinde bulunan, Sarmaşık Kaplıcası termal tesisinde radon aktivite konsantrasyonu ölçümleri yapılmıştır. Kaplıca havuz ortamı, resepsiyon, restoran olmak üzere üç kısımda hava ortamında Cr-39 ve Alpha GUARD PQ 2000 radon dedektörleri yaz ve kış mevsiminde radon gazı ölçümleri yapılmıştır. Yapılan ölçüm sonucunda elde edilen radon gazı değerleri kullanılarak kaplıca ortamında çalışan personel için yıllık etkin doz eşdeğerleri hesaplanmıştır. Ayrıca kaplıca suyu ve kaplıca tesisi içme suyunda radon gazı ölçümü yapılmıştır. Ölçüm sonuçları uluslararası limit seviyeleri ile karşılaştırılmıştır.
\end{abstract}

Anahtar kelimeler: Termal kaplıca, radon, eşdeğer doz.

\section{Determination of Radon Activity Concentration in Fatsa-Sarmaşık Spa (Ordu Province)}

\begin{abstract}
In this study, radon activity concentration measurements were performed at the Sarmaşık Spa thermal facility, located within the borders of Ilica Village, Fatsa District, one of the few geothermal resources in the Black Sea Region. Cr-39 and Alpha GUARD PQ 2000 radon detectors were measured in three parts as spa pool, reception, and restaurant in the air environment in summer and winter seasons. Using the radon gas values obtained as a result of the measurement, annual effective dose equivalents were calculated for the personnel working in the spa environment. In addition, radon gas was measured in the hot spring water and drinking water of the spa facility. Measurement results are compared with international limit levels.
\end{abstract}

Keywords: Thermal spa, radon, equivalent dose.

\section{Giriş}

Termal yeraltı suları ülkelerin değerli doğal kaynaklarından biridir ve sağlık, turizm amaçlı olarak kullanılmaktadırlar. Bu sular yeryüzünün derinliklerinden çıkıp yüzeye ulaşmaktadır ve içerikleri geçtikleri bölgelerin jeolojik yapısı tarafından belirlenmektedir. Yüzeye çıkan sular, yeraltı kayaçlarına ve topraklara temas ederek farklı elementleri de beraberinde taşır. Yeraltı suları geçtikleri kayalardaki radyoaktif maddeleri çözündürerek radyoaktif özellik kazanır. Bu sularda sık rastlanılan belli başlı radyoaktif maddeler ${ }^{40} \mathrm{~K},{ }^{232} \mathrm{Th},{ }^{238} \mathrm{U}$ ' dir. Ayrıca ${ }^{238} \mathrm{U}$ 'in bozunması sonucu ortaya çıkan ${ }^{222} \mathrm{Rn}$ ve ${ }^{226} \mathrm{Ra}$ yeraltı sularında bulunabilir. Yeraltı jeolojik oluşumların içeriğinde bulunan kimyasal bileşikler, suda eriyebilme derecelerine göre yeraltı sularına az ya da çok oranda karışır. Çözünmüş maddelerin miktarı; jeolojik oluşumlarla yeraltı suyunun temas süresine, suyun akış hızına ve sıcaklığına, oluşumun cinsine ve ortamın basıncına bağlı olarak değişir [1-2].

"Sorumlu yazar: selcenduran@ ktu.edu.tr

Geliş Tarihi: 28.01.2020, Kabul Tarihi: 10.05.2020 
İnsanlar sıcak mineralli suların bulunduğu termal tesislere, dinlenme, eğlence-spor, hastalıkları tedavi ve rehabilite etmek amacıyla gitmektedir. Halkın yaygın olarak kullandığı bu suların kimyasal ve radyoaktivite içeriklerinin bilinmesi önemlidir. Bu sulardaki radon içeriği insan sağlığını yakından ilgilendirmektedir. Bu sular üzerine kurulmuş kaplıcalardan faydalanan insanlar belli bir düzeyde radona maruz kalır. Çeşitli rahatsızlıklarına şifa bulmak amacıyla gidilen kaplıcalardaki radyoaktivite düzeyinin tayini ve özellikle doğal radyasyonun büyük çoğunluğunu oluşturduğu için radon düzeyinin belirlenmesi insan sağlığı açısından çok önemlidir. Radyoaktif bir gaz olan radon, solunumla vücuda alındığında iç ışınlama oluşturmaktadır. Dünyadaki akciğer kanserlerinin sebepleri arasında radon gazı solunması önemli bir yer tutmaktadır [3].

Literatürde, kaplıcalarda radyasyon düzeylerini belirlemeye yönelik yapılmış çalışmalar mevcuttur. $\mathrm{Bu}$ tür çalışmaların çoğunun ülkemizde sistematik olmadığı görülürken, dünyadaki diğer ülke kaplıcalarında özellikle radon gazı ön plana alınarak çalışmalar yapılmaktadır.

Ülkemizde yapılan çalışmalar incelendiğinde, 2014 yılında TAEK tarafindan yürütülen bir çalışmada, 70 tesisin kapalı havuzunun bulunduğu alanın havasında ve kaplıca suyundan alınan su örneğinde radon ölçümü yapılmıştır [4]. Kestanbol (Çanakkale-Ezine) kaplıcasında yapılan bir çalışmaya göre, çalışanlar için iç ortamdan kaynaklanan yıllık etkin doz değeri hesaplanmıştır [5]. Dikili jeotermal bölgesindeki radon aktivite konsantrasyonları ölçülmüştür [6]. İzmir Seferihisar Doğanbey fay hattında yer alan termal sularda yapılan bir çalışmada belirlenen istasyonlardan su numuneleri alınıp radon ölçümleri yapılmıştır [7]. Uludağ Üniversitesi Atatürk Rehabilitasyon Uygulama ve Araştırma Merkezi Kükürtlü Kaplıcalarında hava ve suda radon seviyesi belirlenmiştir [8]. Denizli jeotermal bölgesinde beş termal suda radon seviyeleri ölçülmüş deprem ile ilişkilendirilmiştir [9]. Sakarya Kuzuluk ve Taraklı termal sularında radon seviyesi ölçülmüştür [10]. Bursa Bölgesinde 12 termal kaplıcada radon gazı seviyesi 2 sezonluk olarak ölçülmüsstür [11]. Amasya'da 4 kaplıcada radon gazı seviyeleri ölçülmüştür [12]. Yalova termal bölgesinde 5 kaplıca suyunda radon gazı ölçümü yapılmıştır [13]. Rize ve Samsun illerindeki Ayder, İkizdere, Havza, Ladik Kaplıcalarında, aylık ve mevsimlik periyotlarda radon gazı ölçümleri 2 yıl süresince yapılmıştır [14-15].

Bu çalışmanın amacı Ordu ili, Fatsa ilçesinde bulunan Sarmaşık kaplıcası tesisinde, kaplıca havasında ve kaplıca suyunda radon aktivite konsantrasyonu ölçümü yapmak, çalışanlar için radondan kaynaklanan yıllık etkin doz eşdeğerlerini hesaplamaktır. Ordu ilinin iki sıcak su kaynağından biri, tek termal tesisi olma özelliği taşıyan bu kaplıcada daha önce böyle bir çalışma yapılmamıştır.

\section{Materyal ve Metot}

\section{1. Çalıșma Alanı}

Karadeniz Bölgesinde az sayıdaki jeotermal kaynaktan birisi de Fatsa İlçesi, Ilıca Köyü sınırları içerisinde bulunan ve Sarmaşık Kaplıcası olarak tanınan sıcak su kaynağıdır. Fatsa Ilıca Mahallesinde bulunan Sarmaşık Kaplıcası, ilçeye 10 km uzaklıktadır. 2005 yılında MTA Genel Müdürlügü’nün yapmış olduğu Türkiye Jeotermal Envanteri çalışmasında Sarmaşık Kaplıca kaynağının su sıcaklığı $48^{\circ} \mathrm{C}$, debisi $1.2 \mathrm{l} / \mathrm{sn}$ olarak ölçülmüştür. Kaplıca olarak işletilen kurulu ve mevcut bir adet tesis bulunmaktadır [16]. Çalışma yapılan alan Şekil 1'de görülmektedir.

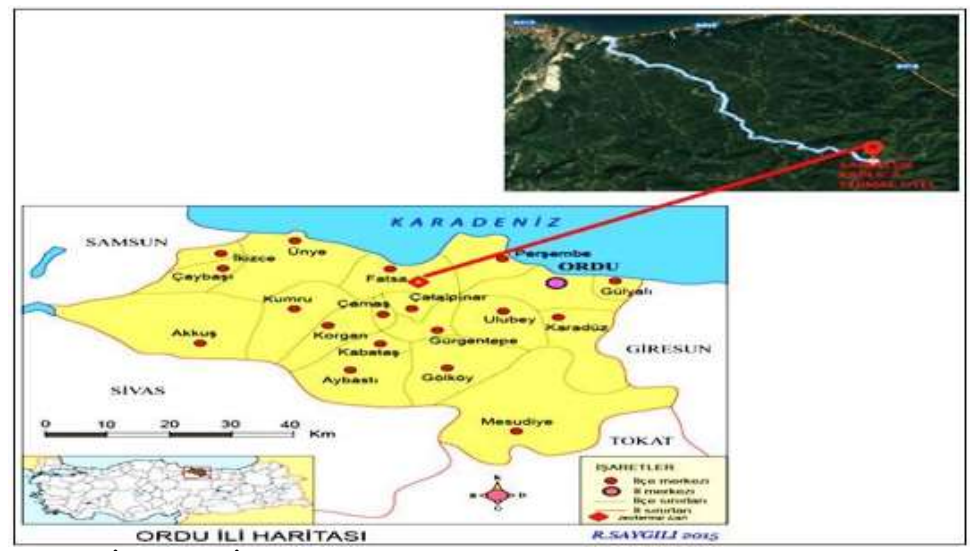

Şekil 1. Ordu İli Fatsa İlçesi Ilıca Mahallesi, Sarmaşık Jeotermal Alan Haritası [16] 


\subsection{Yöntem}

Bina içi radon seviyeleri iki farklı ölçüm tekniği kullanılarak yapılabilir. Bunlardan birisi aktif (anlık olarak), diğeri pasif (belli bir zaman süresince) ölçüm tekniğidir [17]. Bu çalışmada hem pasif ölçüm yapan Cr-39 radon dedektörü hem de aktif olarak ölçüm yapan Alpha GUARD PQ-2000 radon dedektörü kullanılmıştır. Ölçümler kaplıca içerisinde, havuz, resepsiyon ve restoran kısımlarında gerçekleştirilmiştir.

\subsubsection{Pasif Radon Gazı Ölçümü}

Çalışma kapsamı içinde bulunan Sarmaşık Kaplıcasına Cr-39 dedektörleri yaz 2013-2014 (HaziranTemmuz-Ağustos) ve kış (Aralık-Ocak-Şubat) mevsimlerinde 3'er aylık periyotlarla yerleştirilmiştir. Kaplıcada kaldıkları süre boyunca radon gazına maruz kalan dozimetrelerin analizleri ÇNAEM (Çekmece Nükleer Araştırma ve Eğitim Merkezi)'de Radosys otomatik iz sayım sistemi kullanılarak yapılmıştır. Bu çalışmada kullanılan pasif radon dozimetreleri Radosys şirketi tarafindan üretilen $\mathrm{Cr}$-39 dozimetreleri, $35 \times 55 \mathrm{~mm}$ silindirik şekilde olup dedektör çipi plastik kutunun iç alt tarafında, yüzey alanı 10x10 mm ve kalınlığ $1 \mathrm{~mm}$ 'dir. Dozimetrenin yüzeyi polypropylene madde ile kaplanmıştır. Polypropylene madde alfa parçacıklarına duyarlı olup, ${ }^{220} \mathrm{Rn}$ (Toron) ve toz parçacıklarının girmesini engellemektedir. Sadece radon gazı dozimetre içerisine difüzyon yoluyla girmektedir. Radonun bozunması sonucu oluşan alfa parçacıkları dedektör çipin üzerine izler bırakmaktadır. Bu sistem, bilgisayara bağlı gelişmiş bir optik mikroskop, banyo ünitesi ve radon dedektörlerinden oluşmaktadır. Radon gazına maruz kalan CR-39 dozimetreleri üzerinde oluşan alfa izlerinin görünür hale getirilmesi için kimyasal iz kazıma yöntemi kullanılmıştır. Kazıma diskine 36 tane slayt takılabilmekte ve bu, aynı anda 432 tane dedektör çipinin banyo işleminin yapılmasını sağlamaktadır. Her bir slayt sayım ünitesine yerleştirerek okutma işlemi yapılmıştır. CR-39 dozimetresinde, $\mathrm{cm}^{2}$ başına düşen alfa izlerinin yoğunluğu, (200x) optik mikroskop kullanılarak saymıştır. Daha sonra her bir dozimetrenin bırakıldığ yerlere bırakılış ve toplanış tarihleri bilgisayara girilerek kayıtlı olan sistem sayesinde aktiviteler $\mathrm{Bq} / \mathrm{m}^{3}$ cinsinden bulunmuştur.

\subsubsection{Aktif Radon Gazı Ölçümü}

AlphaGUARD aktif radon ölçüm cihazı ile aylık ölçümler 2013 yılının Haziran ayından itibaren kaplıca ortamında yapılmıştır. Bu ölçümlerde cihaz 60 dakika difüzyon modunda çalıştırılmıştır. Yerinde ölçümler yapılmasında kullanılan AlphaGUARD PQ 2000PRO cihazında bulunan iyon odası (alfa spektroskobi pulse sayımı) vasıtası ile ortamın o anki radon değeri ile birlikte hava sıcaklığı, hava basıncı ve havanın nemi gibi diğer parametreler de ölçülmektedir. Taşınabilir nitelikte olan cihazla 2$2.000 .000 \mathrm{~Bq} / \mathrm{m}^{3}$ aralığındaki radon yoğunlukları ölçülmektedir. Cihaz bilgisayara bağlanarak veri depolanmakta ve değerlendirilmektedir. AlphaGUARD Radon detektörü gelişmiş bir atma (puls) iyonlaşma çemberi veya alfa $(\alpha)$ spektroskopisi yöntemi kullanmaktadır. Yüksek Radon ölçüm hassasiyetine sahiptir ve yoğunluk gradiyentleri ile küçük yoğunluk dalgalanmalarını algılayabilecek derecede hassas elektronik yapıya sahiptir. Uzun süreli ölçümler yapabilmektedir ve ölçümler esnasında doğrudan bir güç kaynağına bağlanabildiği gibi yüksek kapasiteli pilleri sayesinde seçilen ölçüm moduna göre 6 aya kadar ölçüm yapabilmektedir. Bunların yanı sıra AlphaGUARD olumsuz sayılabilecek koşullarında, örneğin yüksek nem, yüksek sıcaklık, yüksek titreşim gibi, bakım gerektirmeden ölçüm yapabilmektedir. Şekil 2'de AlphaGUARD PQ 2000PRO detektörü görülmektedir.

İç ortamda ki hava için radon gazından kaynaklanan yıllık etkin doz eşdeğeri UNSCEAR da belirtilen parametreler dikkate alınarak aşağıdaki formüle göre hesaplanmıştır [18].

$A E D E\left(\frac{m S v}{y}\right)=C R n . F . O . D C F$

Burada $\mathrm{C}_{\mathrm{Rn}}$ iç hava ortamındaki radon konsantrasyonu, $\mathrm{F}$, radon ve bozunum ürünlerinden kaynaklanan denge faktörü (0.4), $\mathrm{O}$ iç ortamda geçirilen süre (çalışanlar için y1llık ortalama 2000 saat) ve DCF radondan kaynaklanan doz dönüşüm faktörü 7.9x $10^{-6} \mathrm{mSv} \mathrm{h}^{-1}\left(\mathrm{~Bq} \mathrm{~m}^{-3}\right)^{-1}[18]$. 


\subsubsection{Suda Radon Gazı Ölçümü}

Havuz suyu ve çeşme suyu radon gazı ölçümleri için taşınabilir AlphaGUARD PQ 2000PRO aktif radon ölçüm cihazı kullanılmıştır. Kendi suyunda çalkalanmış 500 ml'lik cam şişelere doldurularak ağzı kauçuk tıpayla kapatılan numunelerin radon ölçümü, radon gazının kısa yarı ömürlü olması nedeniyle yerinde yapılmıştır. Cihaz 1 dakika flow modunda çalıştırılarak bir dakikalık periyotlarla yaklaşık 10'ar dakika ölçüm yapılmıştır. AlphaGUARD cihazı üzerindeki monitörden ölçülen radon gazı konsantrasyonu, radon hata payı, sıcaklık, nem ve basınç değerleri okunabilir. Bu çalışmada hava ve suda radon gazı analizleri en son geliştirilen DataEXPERT yazılımı kullanılarak yapılmıştır.

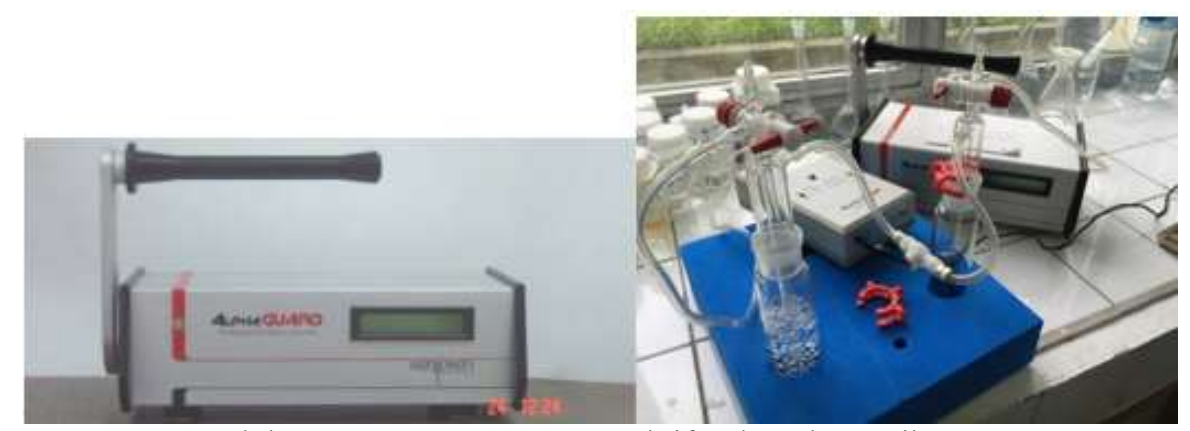

Şekil 2. AlphaGUARD PQ 2000PRO aktif radon ölçüm cihazı ve su kiti

İçme suyundaki radon konsantrasyonu, yağışların ve mevsim şartlarının sularda oluş̧urabileceği değişiklikler sebebiyle, her mevsimde aylık periyotlar ile ölçülmüştür. Su örneklerinde radon konsantrasyonunun belirlenmesi kullanılan denklem aşağıda verilmiştir [19].

Csu $=\left(\right.$ Chava $\left(\left(\frac{\text { Vsistem-Vnumune }}{\text { Vnumune }}\right)+k\right)-$ C0)/1000

$\mathrm{Bu}$ denklemde $\mathrm{C}_{\mathrm{su}}$, su örneğinin radon konsantrasyonunu $(\mathrm{Bq} / \mathrm{l}) ; \mathrm{C}_{\text {hava }}$, ölçüm sonucunda belirtilen konsantrasyon değerini $\left(\mathrm{Bq} / \mathrm{m}^{3}\right) ; \mathrm{C}_{0}$, doğal fon konsantrasyonunu $\left(\mathrm{Bq} / \mathrm{m}^{3}\right) ; \mathrm{V}_{\text {sistem }}$, ölçüm

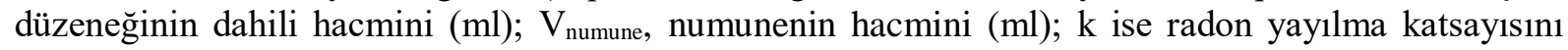
göstermektedir.

Radonlu suların içilmesi durumunda insanlar sindirim sistemi yoluyla bir iç ışınlanmaya da maruz kalmaktadır. Radonlu suyun içilmesinden dolayı alınan yıllık etkin doz eşdeğerleri de Denklem 4 kullanılarak hesaplanmıştır [20].

$A E D E=$ K.C.KM.t

Burada AEDE radonlu suyu içmekten kaynaklanan yıllık etkin doz eşdeğeri (Sv/yıl); K, ${ }^{222} \mathrm{Rn}$ için doz dönüşüm faktörü (yetişkinler için $10^{-8} \mathrm{~Sv} / \mathrm{Bq}$ ); C sudaki ${ }^{222} \mathrm{Rn}$ konsantrasyonu (Bq/l), KM günlük su tüketimi (2 1/gün), t ise tüketim süresi (1 y1l için 365 gün)'dir [20].

\subsubsection{Radon Konsantrasyon Limitleri}

Birçok ülke ve uluslararası organizasyonlar/kuruluşlar, kapalı alanlarda radon seviyeleri için limit değerleri belirlemişlerdir. Ülkemizin ve bazı önemli organizasyonların ev ve işyerleri için tavsiye edilen limit değerleri Tablo 1'de verilmiştir.

Tablo 1. Ev ve iş yerlerinde radon gazı değerleri için ulusal ve uluslararası kuruluşlarca belirlenen limitler [21]

\begin{tabular}{lcc}
\hline Organizasyon & \multicolumn{2}{c}{ Tavsiye edilen limitler $\left(\mathbf{B q} / \mathbf{m}^{\mathbf{3}}\right)$} \\
Ev & İş yeri \\
\hline ICRP & $\leq 300$ & $\leq 1000$ \\
WHO & $\leq 100$ & \\
AB & $\leq 300$ & $\leq 1000$ \\
TAEK & $\leq 400$ & $\leq 1000$ \\
\hline
\end{tabular}


Tablo 1'de verilen sınır değerlerinin aşlıp aşılmadığını anlayabilmek için radon ölçümlerinin yapılması gerekmektedir. Limit seviyesinin aşıldığı durumlarda, radon yoğunluğunu düşürücü önlemler alınmalıdır [21]. İçme suları için radon gazı değerleri ulusal ve uluslararası kuruluşlarca limit değerler belirlenmiştir. Bu değerler Tablo 2'de verilmiştir.

Tablo 2. İçme suyu icin uluslararası kuruluşlarca belirlenen limitler

\begin{tabular}{lcc}
\hline \multicolumn{1}{c}{ Organizasyon } & Limit (Bq/l) & Referans \\
\hline WHO (Word Health Organization ) & 100 & {$[22]$} \\
(USEPA) US Environmental Protection Agency & 11 & {$[23]$} \\
\hline
\end{tabular}

\section{Bulgular ve Tartışma}

Çalışma kapsamında, kaplıca içinde yaz ve kış mevsimi olmak üzere iki dönemlik radon gazı ölçümü yapılmıştır. $\mathrm{Bu}$ ölçümlerde aktif radon gazı ölçümü yapan cihaz 60 dakika difüzyon modunda çalıştırılmıştır. Bu sırada Cr-39 pasif dedektörleri ile mevsimsel olarak kaplıca havasındaki radon gazı ölçümleri yapılarak AlphaGUARD ve Cr-39 radon sonuçları karşılaştırılmıştır. Ayrıca ölçülen radon gazı değerleri dikkate alınarak çalışan personel için yıllık etkin doz eşdeğerleri hesaplanmıştır. Çalışma sonuçları Tablo 3'de görülmektedir.

Tablo 3. Fatsa-Sarmaşık Kaplıcası kaplıca hava ortamında yaz ve kış mevsiminde pasif ve aktif radon dedektörü ile ölçülen radon gazı değerleri ve personel için hesaplanan yıllık etkin doz eşdeğerleri

\begin{tabular}{|c|c|c|c|c|c|c|c|c|}
\hline \multirow{2}{*}{$\begin{array}{c}\text { Tesisin } \\
\text { Bölümleri }\end{array}$} & \multicolumn{2}{|c|}{ Yaz } & \multicolumn{2}{|c|}{ Kış } & \multicolumn{4}{|c|}{ Ortalama } \\
\hline & Pasif & Aktif & Pasif & Aktif & Pasif & Aktif & Pasif & Aktif \\
\hline & \multicolumn{2}{|c|}{$\left(\mathrm{Bq} / \mathrm{m}^{3}\right)$} & \multicolumn{2}{|c|}{$\left(\mathrm{Bq} / \mathrm{m}^{3}\right)$} & $\left(\mathrm{Bq} / \mathrm{m}^{3}\right)$ & $(\mathrm{mSv} / \mathrm{y})$ & $\left(\mathrm{Bq} / \mathrm{m}^{3}\right)$ & $(\mathrm{mSv} / \mathrm{y})$ \\
\hline Havuz & $58 \pm 9$ & $52 \pm 9$ & $106 \pm 14$ & $96 \pm 11$ & $82 \pm 11$ & 0.52 & $74 \pm 6$ & 0.48 \\
\hline Restoran & $105 \pm 10$ & $86 \pm 10$ & $139 \pm 13$ & $128 \pm 16$ & $122 \pm 12$ & 0.77 & $107 \pm 12$ & 0.68 \\
\hline Resepsiyon & $60 \pm 8$ & $49 \pm 8$ & $77 \pm 12$ & $82 \pm 12$ & $68.5 \pm 10$ & 0.43 & $65.5 \pm 10$ & 0.41 \\
\hline
\end{tabular}

Tablo 3 incelendiğinde kaplıcada en yüksek radon gazı değerinin restoran, en düşük radon gazı değerinin resepsiyon kısmında ölçüldüğü görülmüştür. Fakat tüm değerler, işyerleri için izin verilen uluslararası limit değerlerin $\left(1000 \mathrm{~Bq} / \mathrm{m}^{3}\right)$ altındadır.

AlphaGUARD radon monitörünün su probu ile kaplıca suyunda radon gazı değeri ölçülmüştür. Kaplıca suyunda yaz ve kış olmak üzere iki kere radon gazı ölçümü yapılmış, ayrıca kaplıca tesisi içinde bulunan içme suyundan alınan su örneklerinde radon gazı ölçümü yapılmıştır. Ölçüm sonuçları Tablo 4'de görülmektedir. Ayrıca suların pH ve Sıcaklık değerleri de aynı tabloda verilmiştir.

Tablo 4. Kaplıca suyu ve kaplıca tesisinde içme suyu için radon gazı ölçüm sonuçları ve yetişkinler için hesaplanan yıllık etkin doz eşdeğeri

\begin{tabular}{ccccc}
\hline Su & $\mathbf{p H}$ & Sicaklık & ${ }^{\mathbf{2 2 2}} \mathbf{R n}(\mathbf{B q} / \mathbf{l})$ & Doz $(\boldsymbol{\mu s v} / \mathbf{y})$ \\
\hline Kaplıca suyu (yaz) & 8.4 & 46 & $2.5 \pm 0.60$ & 18 \\
Kaplica suyu (kış) & 8.6 & 46 & $3.9 \pm 0.20$ & 28.5 \\
Kaplıca suyu (Ortalama) & & & $3.2 \pm 0.3$ & 23.4 \\
Kaplica tesisi içme suyu (yaz) & 7.3 & 15 & $18 \pm 1.01$ & 131 \\
Kaplıca tesisi içme suyu (kış) & 7.7 & 13 & $14 \pm 1.01$ & 102 \\
Kaplıca tesisi içme suyu(Ortalama) & & & $16 \pm 1$ & 11 \\
\hline
\end{tabular}

Tablo 4'de görüldüğü gibi, kaplıca suyu için ölçülen radon gazı değerleri içme suyu için izin verilen $11 \mathrm{~Bq} / 1$ (US-EPA (1991)) seviyesinden oldukça aşağıda olurken, kaplıca tesisinde içme suyu olarak kullanılan suda radon gazı değeri $11 \mathrm{~Bq} / 1$ den biraz yüksektir.

Fatsa-Sarmaşık kaplıcası hava ortamında ve suyunda radon gazı ölçümü hem aktif hem pasif ölçüm yöntemi kullanılarak 2013-2014 yılı yaz ve kış mevsimlerinde yapılmıştır. Şekil 3'de, aktif (Alpha GARD) ve pasif ölçüm (Cr-39) metotlarının karşılaştırılması verilmektedir. 


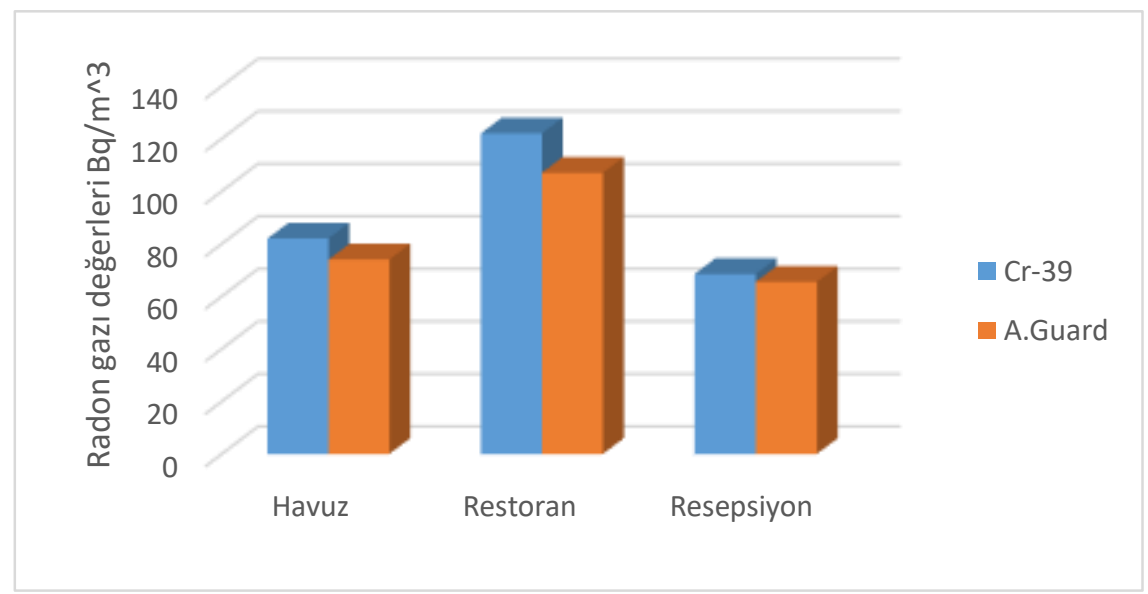

Şekil 3. Kaplıca hava ortamında iki farklı metot ile ölçülen radon gazı değerlerinin karşılaştırılması

Şekil 3'de görüldüğü kaplıca havuzu, resepsiyon ve restoran için Cr-39 ve Alpha GUARD ortalama radon gazı ölçüm sonuçları incelendiğinde Cr-39 pasif dedektör sonuçlarının Alpha GUARD radon gazı dedektöründen daha yüksek olduğu görülmektedir. Cr-39 dedektörleri 3 ay sürecinde kaplıcada kalmıştır, Alpha GUARD detektörü her ay 24 saatlik ölçüm alınıp ölçümlerin ortalaması alınmıştır.

Tablo 5. İç havadaki ve kaplıca suyunda ki radon seviyelerinin ve bu çalışmada belirlenen yıllık etkili dozların literatürdeki çalışmalarla karşılaştırılması

\begin{tabular}{lcccc}
\hline Bölgeler & $\begin{array}{c}\text { Hava } \\
\text { Ortaminda } \\
\text { Radon }\left(\mathbf{B q} / \mathbf{m}^{\mathbf{3}}\right)\end{array}$ & $\begin{array}{c}\text { Suda Radon } \\
\mathbf{B q} / \mathbf{l}\end{array}$ & $\begin{array}{c}\text { Personel Doz } \\
\mathbf{m S v} / \mathbf{y}\end{array}$ & Referanslar \\
\hline İtalya(16 Thermal Spa) & $30-3983$ & - & $0.01-7.03$ & {$[24]$} \\
Brezilya(Termas ve Araxa) & $258-1634$ & - & $1.7-7.5$ & {$[25]$} \\
Sirbistan (Niška Banja) & $140-2810$ & $24.5-648$ & $3-18$ & {$[19]$} \\
Cin (Guangdong) & $30-2144$ & $53.4-292.5$ & - & {$[26]$} \\
Yunanistan (Loutra Edipsou) & $30-1100$ & - & $0.04-1.27$ & {$[27]$} \\
Portekiz (17 Thermal Spa) & $73-3479$ & - & $0.30-1.29$ & {$[28]$} \\
İzmir- Dikili & $31-280$ & -11 & 2.62 & {$[6]$} \\
Kestanbol & $65 \pm 8$ & - & 1.91 & {$[5]$} \\
Cumalı & - & $0.1-16.6$ & - & {$[7]$} \\
Karakoç & - & $0.3-10.2$ & - & {$[7]$} \\
Doğanbey1 & - & $0.3-56.3$ & - & {$[7]$} \\
Doğanbey2 & - & $0.3-7.7$ & - & {$[7]$} \\
Ayder & $108 \pm 17$ & $155 \pm 23$ & 0.9 & {$[14]$} \\
Ilicaköy & $3216 \pm 55$ & $577 \pm 25$ & $13.4-20.3$ & {$[15]$} \\
Havza & $30 \pm 6$ & $82 \pm 9$ & 0.2 & {$[14]$} \\
Ladik & $691 \pm 76$ & $234 \pm 15$ & 3.3 & {$[15]$} \\
Bursa & - & $2.513-82.553$ & - & {$[8]$} \\
Amasya & - & $0.11-0.71$ & $0.28-1.78$ & {$[12]$} \\
Yalova & - & $0.21-5.82$ & $2.44-9$ & {$[13]$} \\
Sakarya & - & $0.19-5.89$ & $1.67-4.74$ & {$[10]$} \\
Bursa & - & $0.26 \pm 0.1-227 \pm 3$ & $2.44-9$ & {$[11]$} \\
Fatsa (Ilıca-Sarmaşıı) & $82 \pm 11$ & $3.2 \pm 0.3$ & 0.52 & Bu Çalışma \\
\hline
\end{tabular}

Tablo 5'de Fatsa- Sarmaşık Kaplıcası için hava ortamında ve su ortamında ölçülen radon gazı değeri ve yıllık etkin doz eşdeğerleri literatürdeki benzer çalışmalarla karşılaştırılmıştır. Yapılan radon gazı ölçüm sonuçları incelenip limit değerler ile karşılaştırıldığında, sonuçların ulusal ve uluslararası kuruluşlarca belirlenen limit seviyelerden düşük olduğu görülmektedir. 


\section{Sonuç ve Öneriler}

Fatsa-Sarmaşık Kaplıcası için yaz ve kış mevsiminde olmak üzere hava ortamı ve kaplıca suyunda radon gazı ölçümü yapılmış ve kaplıca suyu ve hava ortamındaki radon gazı seviyelerinin limit değerlerden daha aşağıda olduğu tespit edilmiştir. Fakat kaplıca ortamında içme suyu olarak kullanılan suyun radon gazı seviyesi EPA'nın izin verdiği seviye olan $11 \mathrm{~Bq} / 1$ değerinden daha yüksektir.

Türkiye' de diğer kaplıcalarda da su ve kapalı yerlerin havasında radon ölçümlerinin yapılması, radon değeri yüksek olan kaplıcalarda sistematik ölçümlerin yapılması önerilmektedir. Sistematik olarak ölçülen (aylık) radon değerleri yüksek olan kaplıcalarda hastalara uygulanan iyileştirme programlarının ve buralarda çalışan personelin çalışma koşullarının gözden geçirilerek gerekli önlemlerin alınması gerekmektedir.

Tablo 5'de görüldüğü gibi, bazı kaplıca sularındaki radon değeri içme suyu için önerilen limit değerlerinden çok yüksektir. Bu suların içilip içilmediğini ve içilmemesi için herhangi bir önlem alınıp alınmadığının araştırılması önerilmektedir. Hesaplanan doz değerleri göz önüne alındığında koruyucu bir önlem olarak özellikle radyoaktivite değeri yüksek olan kaplıcalarda, uzun süreli uygulamalarda ölçüm ve hesapların yetkili doktor ve radyasyon fizikçileri tarafından gözeden geçirilmesi ve buna göre hastalara uygulanan tedavinin yöntem ve uygulama süresine karar verilerek, personelin çalışma süreleri düzenlenmelidir.

\section{Yazarların Katkısı}

Çalışmada tüm yazarlar eşit oranda katkı sunmuştur.

\section{Çıkar Çatışması Beyanı}

Yazarlar arasında herhangi bir çıkar çatışması bulunmamaktadır.

\section{Araştırma ve Yayın Etiği Beyanı}

Yapılan çalışmada, araştırma ve yayın etiğine uyulmuştur.

\section{Kaynaklar}

[1] Valkovic V. 2000. Radioactivity in the Environment. Elsevier Science B.V., Netherlands, 1-681.

[2] Al-Jundi J. 2002. Population Doses from Terrestrial Gamma Exposure in Areas Near to Old Phosphate Mine, Russaifa, Jordan. Radiation Measurements, 35: 23-28.

[3] Wichmann HE., Heinrich J., Gerken M., Kreuzer M., Wellmann J., Keller G., Kreienbrock L. 2002. Domestic radon and lung cancer-current status including new evidence from Germany. International Congress Series, 1225: 247-252.

[4] Türkiye Atom Enerjisi Kurumu, 2014. Türkiye'deki Kaplıca Tesislerinde Radyoaktivite Düzeyinin Araştırılması ve Toplam Etkin Doz Değerlendirilmesi. Teknik Rapor, Ankara.

[5] Çelebi N., Alkan H. 1997. Evaluation of Natural Radiation in the Kestanbol Spa Region. Radiation Protection Dosimety, 69 (3): 227-230.

[6] Yarar Y., Günaydı T., Çelebi N. 2006. Determination of Radon Concentrations of the Dikili Geothermal Area in Western Turkey. Radiation Protection Dosimetry, 118 (1): 78-81.

[7] Camgöz B., Saçı M.M., Bolca M., Özen F., Oruç Ö.E., Demirel N. 2010.Termal Suların Radyoaktivite ve Kimyasal İçeriklerinin İncelenmesi; İzmir, Seferihisar Bölgesi Örneği. Ekoloji, 19 (76): 78-87.

[8] Kılıç N. 2011. Kükürtlü Kaplıcaları Atatürk Rehabilitasyon Merkezindeki Radon Konsantrasyonunun Belirlenmesi. Yüksek lisans Tezi, Uludağ Üniversitesi, Fen Bilimleri Enstitüsü, Bursa.

[9] Erees F.S., Aytas S., Sacb M.M., Yener G., Salk M. 2007. Radon Concentrations in Thermal Waters Related to Seismic Events Along Faults in The Denizli Basin, Western Turkey. Radiation measurements, 42 (1): 80-86. 
[10] Ertuğral F., Yakut H., Tabar E., Akkaya R., Demirci N., Zenginerler Z. 2014. Measurements of Radon Content in the Thermal Waters in Sakarya. Special issue of the International Conference on Computational and Experimental Science and Engineering, 25-29 October, Antalya-Turkey.

[11] Akkaya G., Kahraman A., Koray A., Kaynak G. 2016. Variation in The Radon Concentrations and Outdoor Gamma Radiation Levels in Relation to Different Geological Formations in the Thermal Regions of Bursa, Turkey. Journal of Radiological Protection, 36 (3): 490.

[12] Oner F., Yigitoglu I., Yalim H.A. 2013. Measurements of Radon Concentrations in Spa Waters in Amasya, Turkey. Radiation Protection Dosimetry, 157 (2): 221-224.

[13] Tabar E., Yakut H. 2014. Radon measurements in water samples from the thermal springs of Yalova basin, Turkey. Journal of Radioanalytical and Nuclear Chemistry, 299 (1): 311-319.

[14] Uzun Duran S., Küçükömeroğlu B., Damla N., Taşkın H., Celik N., Cevik U., Ersoy H. 2016. Radioactivity Measurements and Risk Assessments of Spa Waters in Some Areas in Turkey. Isotopes in Environmental and Health Studies, 53 (1): 91-103.

[15] Uzun Duran S., Küçükömeroğlu B., Çevik U., Çelik N., Taşkin H., Ersoy H. 2019. Radioactivity measurements in spas of central and Eastern Black Sea region, Turkey. International Journal of Radiation Research, 17 (3): 383-391.

[16] Şahin T. 2019. Ordu İli Fatsa İlçesi Jeotermal Enerji Potansiyelinin Isıtma Sistemlerinde Kullanımı. Yüksek Lisans Tezi, Ordu Üniversitesi, Fen Bilimleri Enstitüsü, Ordu.

[17] Papastefanou C. 2002. An Overview of Instrumentation for Measuring Radon in Soil Gas and Groundwaters. Journal of Environmental Radioactivity, 63 (3): 271-283.

[18] Nikolov J., Todorovic N., Petrovic P.T., Forkapic S., Mrdja D., Bikit I., Krmar M., Veskovic M. 2012. Exposure to radon in the radon spa Niska Banja. Serbia Radiation Measurements, 47 (6): 443-450.

[19] Genitron Instruments Ltd. AlphaGuard PQ20001 MC50. 1994. Multiparameter radon monitor (Frankfurt: Genitron Instruments Ltd).

[20] Todorovic N., Nikolov J., Forkapic S., Bikit I., Mrdja D., Krmar M., Veskovic M. 2012. Public Exposure to Radon in Drinking Water in Serbia. Applied Radiation and Isotopes, 70 (3): 543-549.

[21] Kürkçüoğlu M.E., Tozun F. 2015. Isparta İl Merkezindeki İş Yerlerinde Atmosferik Radon Ölçümleri. SDU Journal of Science (E-Journal), 10 (1): 62-74.

[22] WHO, 2008. Guidelines for third edition recommendations drinking-water quality. Vol 1., World Health Organization, Geneva.

[23] US-EPA, United States Environmental Protection Agency 1991. National primary drinking water regulations for radionuclides. Federal Register, 33050-33127.

[24] Puglies M., Quarto, M., Roca V. 2014. Radon Concentrations in Air and Water in The Thermal Spas of Ischia Island. Indoor and Built Environment, 23 (6): 823-827.

[25] Campos M.P., Pecequilo B.R.S., Mazzilli B.P. 2010. Rn-222 and Pb-212 Exposures at a Brazilian Spa. Radiation Protection Dosimetry, 141 (2): 1-5.

[26] Song G., Zhang B., Wang X., Gong J., Chan D., Bernett J., Lee S. C. 2005. Indoor radon levels in selected hot spring hotels in Guangdong, China. Science of the Total Environment, 339 (1-3): 63-70.

[27] Geranios A. Nikolopoulos D, Louizi A, Karatzi A. 2004. Multiple radon survey in spa of Loutra Edipsou (Greece). Radiation Protection Dosimetry, 112 (2): 251-258.

[28] Silva A.S., Dinis M.L., Pereira A.J.S.C., Fiúza A. 2015. Radon levels in Portuguese thermal spas. In Proceedings of the, Third International Conference on Radiation and Application in Various Fields of Research, RAD2015, (218), 8-12 June, Budva, Montenegro. 